\title{
Depression as the Middle- and Long-Term Impact for Pre-Symptomatic Testing of Late-Onset Neurodegenerative Disorders
}

\author{
Susana Lêdo ${ }^{1}$ \\ Center for Predictive and Preventive Genetics (CGPP), \\ Institute for Molecular and Cell Biology (IBMC), Porto, Portugal; \\ i3S - Instituto de Investigação e Inovação em Saúde, University Porto, Porto, Portugal \\ Angela Leite \\ Center for Predictive and Preventive Genetics (CGPP) \\ Instituto Superior de Ciências Empresariais e do Turismo, Porto, Portugal, \\ Faculty of Psychology (ULP), Lusophone University of Oporto, Oporto, Portugal \\ Teresa Souto \\ Faculty of Psychology (ULP), Lusophone University of Oporto, Oporto, Portugal \\ Higher Institute of Social Work of Porto (ISSSP), Porto, Portugal \\ Maria Alzira Pimenta Dinis \\ Fernando Pessoa University (UFP) \\ UFP Energy, Environment and Health Research Unit (FP-ENAS), \\ Energy, Environment and Environmental \& Public Health Research Laboratories (3ERL), \\ Porto, Portugal \\ Jorge Sequeiros \\ Center for Predictive and Preventive Genetics (CGPP) \\ Institute for Molecular and Cell Biology (IBMC), Porto, Portugal; \\ i3S - Instituto de Investigação e Inovação em Saúde, University Porto, Porto, Portugal; \\ Instituto de Ciências Biomédicas Salazar (ICBAS), Porto, Portugal.
}

\begin{abstract}
This cross-sectional study investigated depression as the middle- (4 years) and long-term ( 7 and 10 years) psychological impact of pre-symptomatic testing (PST) for 3 autosomal dominant late-onset diseases: Huntington's disease (HD), Machado-Joseph disease (MJD) and familial amyloidotic polyneuropathy (FAP) TTR V30M. It included 203 subjects: 170 (83.7\%) underwent the PST for FAP, 29 $(14.3 \%)$ for HD and $4(2 \%)$ for MJD. Of these 203, 73 were still asymptomatic carriers, $29(14.5 \%)$ were symptomatic, $9(4.5 \%)$ were FAP liver transplanted patients and $89(44.5 \%)$ were non-carriers. Subjects were mainly women $(58.1 \%)$ and married $(66.5 \%)$. The Beck Depression Inventory (BDI) was used to evaluate depression. Scores were higher for symptomatic carriers and for those who have made one or more psychological support consultations over the years. For the formers, the mean scores pointed to mild depression. Asymptomatic carriers and non-carriers had similar scores but it was impossible to differentiate the psychological impact between the medium and long-term. For symptomatic carriers, there
\end{abstract}

Mailing address: R. Júlio Amaral de Carvalho, 45, 4200-135, Porto, Portugal. Phone: 00351226074942. E-mail: susanaledo@gmail.com, angelamtleite@gmail.com, teresassouto@gmail.com,madinis@ufp.edu.pt and jsequeir@ibmc.up.pt

This work was partially supported by National Funds through the Portuguese Foundation for Science and Technology (FCT) and through the Portuguese Human Potential Operational Program/European Social Fund (POPH/FSE), under PhD grant. 
were significant differences between the middle- and long-term. The study indicates that depression occurs only when subjects had previously manifested the first symptoms of their neurologic disease.

Keywords: Depression, late-onset neurologic diseases, Psychological impact, Pre-symptomatic testing.

\section{A Depressão como Indicador do Impacto Psicológico a Médio e Longo Prazo do Teste Pré-Sintomático de Doenças Neurodegenerativas de Início Tardio}

\section{Resumo}

Este estudo transversal investigou a depressão como indicador do impacto psicológico do teste pré-sintomático (TPS) a médio (quatro anos) e longo prazo (de 7 a 10 anos) de doenças neurológicas de início tardio: a doença de Huntington (DH), doença de Machado-Joseph (DMJ) e polineuropatia amiloidótica familiar PAF (TTR V30M). 203 sujeitos participaram no estudo: $170(83,7 \%)$ submetidos ao TPS para PAF, $29(14,3 \%)$ para o DH e 4 (2\%) para DMJ. Destes 203, 73 eram portadores assintomáticos, 29 $(14,5 \%)$ já eram sintomáticos, $9(4,5 \%)$ pacientes com PAF, já tinham realizado o transplante hepático e $89(44,5 \%)$ eram não-portadores. A amostra era constituída maioritariamente por mulheres $(58,1 \%)$ e por sujeitos casados (66,5\%). Utilizou-se o Inventário da Depressão de Beck (BDI). Os scores mais elevados foram observados nos portadores sintomáticos e nos sujeitos que tinham realizado consultas de psicologia com scores indicadores de depressão leve. Os portadores assintomáticos e os não-portadores apresentaram médias semelhantes. Para os portadores sintomáticos, encontrámos diferenças significativas entre o médio e o longo prazo. Este estudo conclui que a depressão pode ocorrer nos indivíduos que já manifestam os primeiros sintomas da respectiva doença neurológica.

Palavras-chave: Depressão, doenças neurológicas de início tardio, impacto psicológico, teste présintomático.

\section{La Depresión como el Indicador de Impacto Psicológico a la Media y Largo Plazo de la Prueba Pre-Sintomática para Enfermedades de Aparición Tardía}

\section{Resumen}

Este estudio transversal investigó la depresión a la media (4 años) y largo plazo ( 7 y 10 años) del impacto psicológico de la prueba pre-sintomática (PPS) para 3 enfermedades autosómicos, dominantes, de aparición tardía: la enfermedad de Huntington (EH), la enfermedad de Machado-Joseph (EMJ) y la polineuropatia amiloide familiare (PAF) o polineuropatia amiloide da transtiretina FAP (TTR V30M). Participaron 203 sujetos: 170 (83,7\%) para PPS para PAF, 29 (14,3\%) para EH y 4 (2\%) para EMJ. De estos 203, 73 estaban todavía portador asintomático, 29 (14,5\%) eran sintomáticos, 9 (4,5\%) fueron PAF pacientes con trasplante hepático y 89 (44,5\%) eran no-portadores. Eran en su mayoría mujeres $(58,1 \%)$ y casados $(66,5 \%)$. Se utilizó el Inventario de Depresión de Beck (IDB). Los puntajes fueron mayores para las portadoras sintomáticas y para aquellos que han hecho consultas de apoyo psicológico con puntuaciones medias de depresión leve. Los portadores asintomáticos y no portadores tuvieron puntajes similares. Para portadores sintomáticos, hubo diferencias significativas entre el medio y largo plazo. Este estudio concluye que la depresión puede ocurrir en personas que ya muestran los primeros síntomas de la enfermedad neurológica.

Palabras clave: Depresión, enfermedades neurológicas de aparición tardía, impacto psicológico, prueba pre-sintomática. 
There are numerous diagnostic or pre-symptomatic tests (PST) for the late-onset neurological disorders (LOND) such as Huntington's disease (HD), Machado-Joseph disease (MJD) or familial amyloidotic polyneuropathy (FAP) TTR V30M (MacLeod et al., 2013; Rolim et al., 2006; Skirton, Goldsmith, Jackson, \& Tibben, 2013; Tibben, Timman, Bannink, \& Duivenvoorden, 1997). The use of PST can predict if a person will develop the first symptoms sometime in the near future (Lerman, 1997; Rolim et al., 2006; Tibben et al., 1997). Several studies tried to understand the psychosocial short-term impact (i.e., during one year, of this type of genetic testing; Codori, Slavney, Rosenblatt, \& Brandt, 2004; Lêdo, 2002; Lêdo, Leite, \& Sequeiros, 2013; Lerman, 1997; Michie, Bobrow, \& Marteau, 2001; Rolim et al., 2006; Tibben, 2007; Tibben et al., 1997), but very few have studied such impact in the middle- and long-term period of time (Decruyen et al., 2003, 2004; Gargiulo et al., 2009; Gonzalez et al., 2012; Timman, Roos, Maat-Kievit, \& Tibben, 2004).

During the first year of the predictive protocol program, aimed at the short-term impact evaluation, developed at the Center for Predictive and Preventive Genetics (CGPP) at the Institute of Molecular and Cell Biology (IBMC), University of Porto, a national reference model was evaluated for genetic counseling and psychosocial support for people at-risk of suffering of such progressive and debilitating diseases that have currently no effective treatment or cure (Rolim et al., 2006; Sequeiros, 1996a). The middle- and long-term impact evaluation were studied based on the subjects' initial medical records, considering only those subjects who underwent PST for a genetic disease.

\section{The Diseases Studied}

HD, MJD and FAP are three examples of diseases characterized by monogenic autosomal, dominant, late-onset, and clinically considered as neurodegenerative diseases. These three diseases are incurable and highly debilitating, and may exhibit a broad spectrum of symptoms (Sequeiros, 1996b).
HD (Almqvist, Bloch, \& Hayden, 1999; Decruyenaere, Evers-Kiebooms, \& Van Den Berghe, 1997; Tibben, 2007; Tibben et al., 1997) is the most studied of the three above mentioned neurodegenerative diseases, largely due to its early discovery by Guselli and colleagues in 1983 of the relevant genetic marker (Codori, Hanson, \& Brandt, 1994). PST for HD began in 1986, in Canada and in the United States of America (MacLeod et al., 2013; Tibben et al., 1997), having been extended to Europe at the 1990's (Almqvist et al., 1999; Codori et al., 2004; Decruyenaere et al., 1997). The literature already presents some long-term psychosocial impact studies of the HD predictive test (Decruyenaere et al., 2003, 2004; Gargiulo et al., 2009; Lêdo et al., 2013; Timman et al., 2004). Gargiulo et al. (2009) interviewed 119 subjects with PST result of non-carriers and carriers after a mean delay of 3.7 years of knowing the result of the genetic testing they underwent. Depression was frequent in asymptomatic carriers (58\%). The self reported impact of the test showed that $27 \%$ of non-carriers did not cope well with a favorable result, and a significant percentage of noncarriers (24\%) were depressed during the followup period of the test. Only a previous episode of depression could be considered a predictive factor for later depression after genetic testing, in both carriers and non-carriers of the HD mutation. Timman et al. (2004) described a 7-10 years psychological effects of PST for HD in 142 individuals and their 104 partners. Carriers and their partners were more distressed immediately after receiving the test result, although their outlooks improved somewhat in the 2-3 year post-test period. They became, on the contrary, more pessimistic when approaching the age of onset of the disease. Carriers who felt lost during the follow-up period after the disclosure of test results, reported more distress on the pre-test than the retained carriers. The same authors suggested that studies that report few harmful effects may have underestimated the real impact (Timman et al., 2004). Decruyenaere et al. (2003) have carried out a 5 year longitudinal study on psychological distress after predictive testing for HD and on correlates of post-test distress. 
Twenty-four carriers and 33 non-carriers have participated in the follow-up study. Three points in time were included: baseline, 1 year and 5 years post-test. Five years after the test, the mean distress scores of both carriers and non-carriers were within the normal range. Carriers did not differ from non-carriers in terms of the mean general distress. Compared to non-carriers, however, carriers had significantly less positive feelings and were more consciously avoiding HD related situations and thoughts. The authors suggested that these findings reflect the carriers' conscious and unconscious attempt to escape from pessimism and to minimize negative consequences of the test result (Decruyenaere et al., 2003). Psychological distress, 5 years post-test, was significantly associated with ego-strength. Except for intrusion and avoidance, distress was also associated with test motivation. Compared with the baseline level, the mean depression, general and specific anxiety values had significantly decreased 1 year and 5 years posttest. This evolution was independent of the test result. The pattern of post-test anxiety differed over time, depending on the test motivation.

Two very specific Portuguese diseases, MJD and FAP, have also a severe neurodegenerative pathway, without effective treatment or cure. For MJD, it is important to highlight the frequent signs of cerebellar ataxia, progressive external ophthalmoplegia and pyramidal signs (Coutinho, 1996; Sequeiros, 1996a, 1996b). In 1993, the gene of MJD was finally located on chromosome 14 by a group of researchers led by Takiyama et al. (1993). This was later confirmed in the Portuguese kindred by Sequeiros (1996c). The genetic mutation present in FAP leads to the production of an amyloid protein, which is immunologically related to transthyretin (TTR) that is abnormally degraded, precipitated and stored in body tissues as an amyloid substance and then deposited in various organs leading these patients to experience progressive limitations (Saraiva \& Costa, 1986).

Pre-symptomatic diagnosis for FAP has been available since 1984 (Lerman, 1997; Sequeiros, 1996c). Several psychosocial studies have been conducted among families at-risk and their descendants in order to study the short-term psychosocial impact of their PST (Codori et al., 2004; Lêdo, 2002; Leite, 2006; Michie et al., 2001; Paneque et al., 2009; Rolim et al., 2006; Tibben et al., 1997) and, in general, no negative outcomes were shown. There is, however, a lack of research concerning the middle- and long-term PST psychological impact (Almqvist, Brinkman, Wiggins, \& Hayden, 2003; Timman et al., 2004). Therefore, it becomes important to study the middle- and long-term psychological impact of information about the genetic status of subjects who underwent the PST and compare the Portuguese findings with the few foreign studies for HD.

The main objective of the research addressed in the present study is to contribute to increase the knowledge about the follow-up studies investigating the long-term consequences of PST, as suggested by Timman et al. (2004), in the context of the Portuguese reality that includes other diseases of late-onset beyond HD. Consequently, symptomatic depression was studied and the hypothesis addressed was that the levels of depression would increase for carriers and decrease for non-carriers in the middle- and long-term after PST result disclosure and the oncoming age of onset.

\section{Methods and Instruments}

This descriptive cross-sectional study was based upon the data gathered from the individual's medical records after completing one year PST for genetic autosomal dominant late-onset diseases (MJD, HD and FAP) in CGPP, at least three years before the study, the only criteria of inclusion in this study, both for carriers as for non-carriers. All subjects who accepted to undergo one year protocol, were previously informed about the purpose of the research and have signed a written consent authorizing the use of their data for scientific research purposes. The guidelines for the investigation were accepted by the IBMC ethic committee.

The subjects were contacted only one time, during which the socio-demographic questionnaire and the Beck Depression Inventory (BDI) 
were both filled in (Beck, Mendelson, Mock, \& Erbaugh, 1961; Beck, Steer, Ball, \& Ranieri, 1996).

\section{Participants}

A survey and updating was made of the 686 subjects' addresses that had completed their respective PST protocol at least three years ago, before sending the set of specific questionnaires by mail. Of the 686 subjects, only 203 subjects answered, making them effective participants of the study.

In terms of the socio-demographic main features, and after analyzing Table 1, it is possible to observe that $58.1 \%$ participants were female and that, in terms of age, the majority of the participants ranged up to 30 years. Most of the subjects who at the completion of the one year PST protocol were single, are now actually married. Regarding the profession, participants had mainly professions that involved some responsibilities and had completed higher education ( $1^{\text {st }}$ Graffar Index). Second in range, appear those participants that are retired. Most subjects underwent the PST for FAP (83.7\%) and had the carrier genetic status $(36.5 \%)$. It was important to consider, among carriers, those who meanwhile became symptomatic for their disease (14.5\%) and, in the case of FAP, if some of these symptomatic patients have already had liver transplantation (4.5\%). Out of the 203 subjects that answered, there was the need to establish three cutoff points that signal out for how long subjects had been informed about their PST result: $32.2 \%$ had known their genetic status for 4 years, $47 \%$ for 7 years and $20.8 \%$ for 10 years.

Chi-Square $\left(\chi^{2}\right)$ was calculated to assess whether there were significant differences between the samples at the cutoff points. Differences were only found regarding the type of disease.

Table 1

Description of the Total Sample by Years of Protocol Disclosure

\begin{tabular}{|c|c|c|c|c|c|c|c|c|}
\hline \multirow{3}{*}{ Variable } & \multirow{3}{*}{$(n=203)$} & \multirow{3}{*}{$(\%)$} & \multicolumn{6}{|c|}{ Number of Years of Protocol } \\
\hline & & & \multicolumn{2}{|c|}{4} & \multicolumn{2}{|c|}{7} & \multicolumn{2}{|c|}{10} \\
\hline & & & $n$ & $\%$ & $n$ & $\%$ & $n$ & $\%$ \\
\hline \multicolumn{9}{|c|}{$\begin{array}{l}\text { Gender } \\
\left(\chi^{2}=2.020 ; d f=2 ; p=.364\right)\end{array}$} \\
\hline Female & 118 & 58.1 & 33 & 58.1 & 58 & 61.1 & 26 & 61.9 \\
\hline Male & 85 & 41.9 & 32 & 41.9 & 37 & 38.9 & 16 & 38.1 \\
\hline \multicolumn{9}{|c|}{$\begin{array}{l}\text { Age } \\
\left(\chi^{2}=9.636 ; d f=10 ; p=.473\right)\end{array}$} \\
\hline$\leq 30$ years & 88 & 43.3 & 32 & 49.2 & 40 & 42.1 & 15 & 35.7 \\
\hline $31-40$ years & 62 & 30.5 & 14 & 21.5 & 32 & 33.7 & 16 & 38.1 \\
\hline $41-50$ years & 20 & 9.9 & 7 & 10.8 & 10 & 10.5 & 3 & 7.1 \\
\hline $51-60$ years & 22 & 10.8 & 9 & 13.8 & 6 & 6.3 & 7 & 16.7 \\
\hline $61-70$ years & 8 & 3.9 & 2 & 3.1 & 5 & 5.3 & 1 & 2.4 \\
\hline$\geq 71$ years & 3 & 1.5 & 1 & 1.5 & 2 & 2.1 & 0 & 0.0 \\
\hline \multicolumn{9}{|c|}{ Marital status (At PST) } \\
\hline Single & 104 & 51.2 & & & & & & \\
\hline Married & 89 & 43.8 & & & & & & \\
\hline Divorced & 5 & 2.5 & & & & & & \\
\hline Widow & 2 & 1.0 & & & & & & \\
\hline
\end{tabular}




\begin{tabular}{|c|c|c|c|c|c|c|c|c|}
\hline \multirow{3}{*}{ Variable } & \multirow{3}{*}{$(n=203)$} & \multirow{3}{*}{$(\%)$} & \multicolumn{6}{|c|}{ Number of Years of Protocol } \\
\hline & & & \multicolumn{2}{|c|}{4} & \multicolumn{2}{|c|}{7} & \multicolumn{2}{|c|}{10} \\
\hline & & & $n$ & $\%$ & $n$ & $\%$ & $n$ & $\%$ \\
\hline Married & 132 & 66.5 & 30 & 66.5 & 65 & 69.9 & 30 & 75.0 \\
\hline Divorced & 10 & 5.0 & 1 & 5.0 & 5 & 5.4 & 1 & 2.5 \\
\hline Widow & 3 & 1.5 & 0 & 0.0 & 2 & 2.1 & 1 & 2.5 \\
\hline
\end{tabular}

Profession

$\left(\chi^{2}=9.897 ; d f=14 ; p=.770\right)$

\begin{tabular}{|c|c|c|c|c|c|c|c|c|}
\hline Retired & 40 & 19.7 & 15 & 23.1 & 15 & 15.8 & 10 & 23.8 \\
\hline Unemployed & 19 & 9.4 & 7 & 10.8 & 8 & 8.4 & 4 & 9.5 \\
\hline Student & 15 & 7.4 & 4 & 6.2 & 9 & 9.5 & 2 & 4.8 \\
\hline $1^{\text {st }}$ Graffar index & 59 & 29.1 & 19 & 29.2 & 29 & 30.5 & 11 & 26.2 \\
\hline $2^{\text {nd }}$ Graffar index & 11 & 5.4 & 2 & 6.2 & 6 & 6.3 & 1 & 2.4 \\
\hline $3^{\text {rd }}$ Graffar index & 4 & 2.0 & 3 & 4.6 & 0 & 0.0 & 1 & 2.4 \\
\hline $4^{\text {th }}$ Graffar index & 22 & 10.8 & 6 & 9.2 & 11 & 11.6 & 5 & 11.9 \\
\hline $5^{\text {th }}$ Graffar index & 33 & 16.3 & 7 & 10.8 & 17 & 17.9 & 8 & 19.0 \\
\hline
\end{tabular}

Type of Disease

$\left(\chi^{2}=15.880 ; d f=4 ; p=.003\right)$

$\begin{array}{lcccccccc}\text { FAP } & 170 & 83.7 & 46 & 70.8 & 84 & 88.4 & 39 & 92.9 \\ \text { HD } & 29 & 14.3 & 15 & 23.1 & 11 & 11.6 & 3 & 7.1 \\ \text { MJD } & 4 & 2.0 & 4 & 6.2 & 0 & 0.0 & 0 & 0.0\end{array}$

PST Result

$\left(\chi^{2}=0.369 ; d f=2 ; p=.831\right)$

Non-carrier

Carrier

Current Clinical Status

$\left(\chi^{2}=4.329 ; d f=6 ; p=.632\right)$

Non-carrier

Asymptomatic Carrier

Symptomatic Carrier

Liver Transplanted

(FAP carriers)

$\begin{array}{llllllll}91 & 44.8 & 30 & 46.2 & 43 & 45.3 & 17 & 40.5 \\ 112 & 55.2 & 35 & 53.8 & 52 & 54.7 & 25 & 59.5\end{array}$

Note. $\chi^{2}=$ Chi-Squared Distribution; $d f=$ degrees of freedom; $p=p$-value. $\mathrm{PST}=$ pre-symptomatic tests; FAP $=$ familial amyloidotic polyneuropathy; HD = Huntington's disease; MJD = Machado-Joseph disease.

When analyzing Table 1, it is possible to understand that participants are distributed by the three cutoff points of 4,7 and 10 years. However, if focusing on the group of subjects who completed the protocol seven years ago, the mean age increased (31-40 years) and, in terms of the profession, the number of retired participants has also increased.

\section{Instruments}

The socio-demographic variables - gender, age, profession, and marital status - and a clinical 
variable - current clinical status - were gathered based on the answers to a questionnaire sent to the participants (carriers and non-carriers).

The variable depression was assessed using the Portuguese version of BDI (Beck et al., 1961; Beck et al., 1996). This inventory was translated and adapted since 1973 (Vaz-Serra \& Pio-Abreu, 1973a, 1973b) and identifies depression symptoms such as sadness, pessimism, sense of failure, dissatisfaction, guilt, expectation of punishment, disappointment with himself, self-criticism, suicidal ideation, tearfulness, irritability, social withdrawal, indecisiveness, body image distortion, loss of energy, changes appetite, insomnia, fatigue, weight loss, health concerns and loss of libido (Beck et al., 1996). It is a self-response inventory consisting of 21 items, designed to measure the severity of depressive symptoms. Each item has 4, 5 or 6 statements, sorted according to the symptom's severity, which may be none, mild, moderate or severe.

The subject's task is to choose the statement that is closest to its current state. The study of BDI psychometric properties showed that it is an instrument with good reliability, as mentioned by Beck, and also good validity, since Cronbach's alpha $(\alpha)$ is .84 (Pinto-Gouveia, 1990).

Regarding the Portuguese population, VazSerra and Pio-Abreu (1973a, 1973b) suggested that the value of 12 is the cutoff point above which the difference between normal and depressed population is set.

\section{Procedure}

The work began with the group of subjects who signed the written informed consent and had completed the PST one year protocol for genetic counseling and psychosocial assessment within CGPP for more than three years, regardless of the subjects being diagnosed as carriers or noncarriers for the three studied diseases. Then, by mail, a set of specific questionnaires was sent depending on whether the subject was a carrier or non-carrier. Besides containing some items to update the socio-demographics information, as marital status, profession or significant life changes, the questionnaires also included some questions about the current clinical status - in carriers, if a person remained asymptomatic or if that person had already presented symptoms - and, finally, some questions concerning the existence of any link to the context of the respective disease or, on the contrary, a withdrawal from the reality associated with the disease, using some psychological scales such as BDI. A cover letter containing information about the researcher, the nature and objectives of the study and recalling the principle of confidentiality displayed when the subject was originally registered in the protocol for the PST, was also included.

A period of 6 months was determined to receive the participant's responses by mail. Afterwards, those answers were integrated into a database, specifically developed using IBM SPSS Statistics 19.

\section{Data Analysis}

The statistical analysis was performed using the IBM SPSS Statistics 19 (Norusis, 2011). Two distinct types of analysis were carried out: descriptive and inferential.

In terms of the descriptive analysis, the measures used were frequencies, mean, standard deviation $(S D)$, and minimum and maximum values. In terms of the inferential analysis carried out, it became a necessary complement and the options made have included bivariate statistical analysis - ANOVA and bivariate correlation - and prediction for the identification of groups - factor analysis and discriminant analysis.

\section{Results}

Analysis of the Items Frequency in the Sample Considering the Gender Variable

The twenty one descriptive items of the scale were analyzed considering the mean, $S D$ and percentage of symptomatic responses - namely, those scored with 1, 2 or 3 points - for the total sample and for carriers and non-carriers. It was possible to confirm that there were statistically significant differences in relation to item 8 (selfcriticism), item 15 (loss of energy), item 17 
(fatigue) and item 20 (health concerns), and that carriers had higher values in all items than noncarriers.

The items presenting higher percentage of symptomatic responses were loss of interest, irritability and fatigue - for carriers - and loss of interest, self-criticism and change of sleep patterns - for non-carriers.

When comparing the items' mean between men and women, no statically significant differences were found, except regarding crying and loss of sexual interest items, which were higher in women. This phenomenon is, however, common in the general population.

\section{Descriptive Analysis of BDI Total Scores and Subscales}

The descriptive analysis of the results of the BDI total scores and subscales for: (a) the total sample, (b) carriers and non-carriers samples and (c) the specific samples resulting from the three cutoff points considered was performed.

As it is possible to observe in Table 2, carriers presented higher values than non-carriers and those differences were statistically significant for the BDI total scores $(F=5.138 ; d f=1 ; p$ $=.025)$ and for BDI somatic subscale $(F=6.013$; $d f=1 ; p=.015)$.

Table 2

Results of the BDI Total Scores and Subscales $(M, S D$ and $\alpha$ ) for the Total-Sample Carriers and NonCarriers Subsamples and Symptomatic and Non-Symptomatic Carriers

\begin{tabular}{|c|c|c|c|c|c|c|}
\hline \multirow{2}{*}{ Variable } & \multicolumn{2}{|c|}{ Total sample } & \multicolumn{2}{|c|}{ Carriers } & \multicolumn{2}{|c|}{ Non-carriers } \\
\hline & $M$ & $S D$ & $M$ & $S D$ & $M$ & $S D$ \\
\hline \multirow{2}{*}{ BDI Total Scores* } & 6.49 & 7.95 & 7.67 & 8.61 & 5.08 & 6.88 \\
\hline & \multicolumn{2}{|c|}{$(\alpha=.893)$} & \multicolumn{2}{|c|}{$(\alpha=.892)$} & \multicolumn{2}{|c|}{$(\alpha=.893)$} \\
\hline \multirow{2}{*}{ BDI Cognitive-Affective Subscale } & 3.94 & 5.35 & 4.60 & 5.03 & 3.13 & 4.76 \\
\hline & \multicolumn{2}{|c|}{$(\alpha=.863)$} & \multicolumn{2}{|c|}{$(\alpha=.862)$} & \multicolumn{2}{|c|}{$(\alpha=.859)$} \\
\hline \multirow{4}{*}{ BDI Somatic Subscale* } & 2.60 & 3.39 & 3.14 & 3.83 & 1.95 & 2.65 \\
\hline & \multicolumn{2}{|c|}{$(\alpha=.769)$} & \multicolumn{2}{|c|}{$(\alpha=.785)$} & \multicolumn{2}{|c|}{$(\alpha=.711)$} \\
\hline & \multicolumn{2}{|c|}{ Total sample } & \multicolumn{2}{|c|}{ Symptomatic carriers } & \multicolumn{2}{|c|}{ Non-symptomatic carriers } \\
\hline & $M$ & $S D$ & $M$ & $S D$ & $M$ & $S D$ \\
\hline \multirow{2}{*}{ BDI Total Scores* } & 6.49 & 7.95 & 12.69 & 9.05 & 5.26 & 7.02 \\
\hline & \multicolumn{2}{|c|}{$(\alpha=.893)$} & \multicolumn{2}{|c|}{$(\alpha=.847)$} & \multicolumn{2}{|c|}{$(\alpha=.890)$} \\
\hline \multirow{2}{*}{ BDI Cognitive-Affective Subscale* } & 3.94 & 5.35 & 6.74 & 6.25 & 3.45 & 4.84 \\
\hline & \multicolumn{2}{|c|}{$(\alpha=.863)$} & \multicolumn{2}{|c|}{$(\alpha=.823)$} & \multicolumn{2}{|c|}{$(\alpha=.860)$} \\
\hline \multirow{2}{*}{ BDI Somatic Subscale* } & 2.60 & 3.39 & 6.22 & 4.09 & 1.76 & 2.77 \\
\hline & \multicolumn{2}{|c|}{$(\alpha=.769)$} & \multicolumn{2}{|c|}{$(\alpha=.666)$} & \multicolumn{2}{|c|}{$(\alpha=.755)$} \\
\hline
\end{tabular}

Note. $M=$ Mean; $S D=$ Standard deviation.

*Differences between carriers and non-carriers and symptomatic and non-symptomatic carriers at $p<.05$ at $p<.05$.

In Table 2 , it is possible to observe that symptomatic carriers presented higher values than non-symptomatic carriers and that those differences were statistically significant for the BDI total scores $(F=18.087 ; d f=1 ; p=.001)$,
BDI cognitive-affective $(F=7.657 ; d f=1 ; p=$ $.007)$ and BDI somatic subscale $(F=38.221 ; d f$ $=1 ; p=.001)$.

Concerning the three cutoff points considered, the means, as well as the $S D$, were very 
Table 3

Results of the BDI Total Scores and Subscales $(M, S D$ and $\alpha)$ at the Three Cutoff Points $(4,7$ and 10 years) for the Total Sample

\begin{tabular}{|c|c|c|c|c|c|c|}
\hline \multirow{2}{*}{ Variable } & \multicolumn{2}{|c|}{4 Years } & \multicolumn{2}{|c|}{7 Years } & \multicolumn{2}{|c|}{10 Years } \\
\hline & $M$ & $S D$ & $M$ & $S D$ & $M$ & $S D$ \\
\hline \multirow{2}{*}{ BDI Total Scores } & 6.63 & 8.54 & 6.63 & 8.00 & 6.03 & 7.09 \\
\hline & \multicolumn{2}{|c|}{$(\alpha=.898)$} & \multicolumn{2}{|c|}{$(\alpha=.901)$} & \multicolumn{2}{|c|}{$(\alpha=.866)$} \\
\hline \multirow{2}{*}{ BDI Cognitive-Affective Subscale } & 4.19 & 5.55 & 4.04 & 5.60 & 3.33 & 4.50 \\
\hline & \multicolumn{2}{|c|}{$(\alpha=.856)$} & \multicolumn{2}{|c|}{$(\alpha=.881)$} & \multicolumn{2}{|c|}{$(\alpha=.825)$} \\
\hline \multirow{2}{*}{ BDI Somatic Subscale } & 2.44 & 3.74 & 2.68 & 3.28 & 2.73 & 3.12 \\
\hline & \multicolumn{2}{|c|}{$(\alpha=.810)$} & \multicolumn{2}{|c|}{$(\alpha=.778)$} & \multicolumn{2}{|c|}{$(\alpha=.680)$} \\
\hline
\end{tabular}

Note. $M=$ Mean; $S D=$ Standard deviation.

* No statistically significant differences were found in relation to the cutoff points regarding the BDI total scores, the BDI cognitive-affective and the BDI somatic subscales.

similar for the BDI total scores and subscales (results presented in Table 3) and there are no statistically significant differences for the BDI total scores, BDI cognitive-affective and BDI somatic for the total sample.

The correlations between BDI total scores $(r=-.027, p=.724)$ and BDI cognitive-affective $(r=-.053, p=.465)$ and BDI somatic $(r=.033$, $p=.649)$ subscales and the cutoffs were calculated, and it was possible to confirm that these correlations are not significant.

Considering the three cutoff points and the test result (carrier and non-carrier), no statistically significant differences were found regarding the BDI total scores, the BDI cognitive-affective and the BDI somatic subscales for sample of carriers (results presented in Table 4), as well as no significant correlations were found between BDI total scores $(r=-.102, p=.304)$ and BDI cognitive-affective $(r=-.117, p=.231)$ and BDI somatic $(r=-.045, p=.647)$ subscales, and the cutoff points for this sample.

Taking into account the three cutoff points and the current status of individuals, statistically significant differences were found for the sample of symptomatic carriers relating the BDI total scores $(F=4.017, d f=2 ; p=.032)$. The differences found for the BDI cognitive-affective and the BDI somatic subscale are, however, not significant (Table 4). Significant correlations were found between the BDI total scores $(r=-.506$, $p=.008)$ and BDI somatic $(r=-.447, p=.019)$ and BDI cognitive-affective $(r=-.418, p=.030)$ subscales, and the cutoff points for this sample. Since these last correlations are negative, it is possible to conclude that as time goes by, the depression's value decreases.

Considering the three cutoff points and the current status of carriers (symptomatic and asymptomatic), no statistically significant differences were found for the sample of asymptomatic carriers relating the cutoff points in what concerns the BDI total scores, the BDI cognitive-affective and BDI somatic subscales (Table 4). Similarly, there are no significant correlations between BDI total scores $(r=$ $-.034, p=.778)$ and BDI cognitive-affective $(r$ $=-.097, p=.419)$ and BDI somatic $(r=-.081, p$ $=.506)$ subscales, and the cutoff points for this sample.

Finally, and taking also into account the three cutoff points, no statistically significant differences were found considering the cutoff points and the BDI total scores, the BDI somatic and the BDI cognitive-affective subscales for the sample of non-carriers (results presented in Table 5). The correlations between the BDI total scores $(r=-.087, p=.428)$, and the BDI cognitive-affective $(r=-.034, p=.757)$ and the BDI somatic subscales $(r=.164 ; p=.131)$ and the cutoff points are not significant for this sample. 
Table 4

Results of the BDI Total Scores and Subscales $(M, S D$ and $\alpha$ ) at the Three Cutoff Points (4, 7 and 10 years) for the Carriers (in general) and Symptomatic and Non-Symptomatic Carriers Samples

\begin{tabular}{|c|c|c|c|c|c|c|}
\hline \multirow[b]{2}{*}{ Variable } & \multicolumn{2}{|c|}{4 Years } & \multicolumn{2}{|c|}{7 Years } & \multicolumn{2}{|c|}{10 Years } \\
\hline & $M$ & $S D$ & $M$ & $S D$ & $M$ & $S D$ \\
\hline \multirow{2}{*}{ BDI Total Scores* } & 8.46 & 9.39 & 7.93 & 8.17 & 5.96 & 8.38 \\
\hline & \multicolumn{2}{|c|}{$(\alpha=.893)$} & \multicolumn{2}{|c|}{$(\alpha=.885)$} & \multicolumn{2}{|c|}{$(\alpha=.909)$} \\
\hline \multirow{2}{*}{ BDI Cognitive-Affective Subscale* } & 5.31 & 5.94 & 4.65 & 5.80 & 3.43 & 5.27 \\
\hline & \multicolumn{2}{|c|}{$(\alpha=.848)$} & \multicolumn{2}{|c|}{$(\alpha=.871)$} & \multicolumn{2}{|c|}{$(\alpha=.873)$} \\
\hline \multirow{2}{*}{ BDI Somatic Subscale* } & 3.14 & 4.39 & 3.43 & 3.56 & 2.58 & 3.53 \\
\hline & \multicolumn{2}{|c|}{$(\alpha=.815)$} & \multicolumn{2}{|c|}{$(\alpha=.756)$} & \multicolumn{2}{|c|}{$(\alpha=.779)$} \\
\hline & \multicolumn{6}{|c|}{ For the symptomatic carriers sample } \\
\hline & \multicolumn{2}{|c|}{4 Years } & \multicolumn{2}{|c|}{7 Years } & \multicolumn{2}{|c|}{10 Years } \\
\hline & $M$ & $S D$ & $M$ & $S D$ & $M$ & $S D$ \\
\hline \multirow{2}{*}{ BDI Total Scores** } & 18.33 & 9.03 & 11.00 & 8.26 & 5.50 & 4.04 \\
\hline & \multicolumn{2}{|c|}{$(\alpha=.795)$} & \multicolumn{2}{|c|}{$(\alpha=.848)$} & \multicolumn{2}{|c|}{$(\alpha=.450)$} \\
\hline \multirow{2}{*}{ BDI Cognitive-Affective Subscale* } & 10.00 & 6.40 & 5.86 & 6.20 & 2.50 & 1.73 \\
\hline & \multicolumn{2}{|c|}{$(\alpha=.796)$} & \multicolumn{2}{|c|}{$(\alpha=.826)$} & \multicolumn{2}{|c|}{$(\alpha=.301)$} \\
\hline \multirow{2}{*}{ BDI Somatic Subscale* } & 8.33 & 2.55 & 5.92 & 3.55 & 3.20 & 2.78 \\
\hline & \multicolumn{2}{|c|}{$(\alpha=.652)$} & \multicolumn{2}{|c|}{$(\alpha=.633)$} & \multicolumn{2}{|c|}{$(\alpha=.297)$} \\
\hline & \multicolumn{6}{|c|}{ For the non-symptomatic carriers sample } \\
\hline & & & & & & \\
\hline & $M$ & $S D$ & $M$ & $S D$ & $M$ & $S D$ \\
\hline DDI Tatol Ceare** & 5.08 & 6.97 & 5.97 & 7.94 & 4.13 & 5.72 \\
\hline 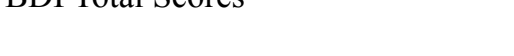 & & & & & & \\
\hline BDI Coonitive-Affective Subscole* & 3.84 & 4.96 & 3.61 & 5.28 & 2.47 & 3.72 \\
\hline 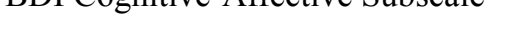 & & & & & & \\
\hline DDI Somatic Cubcollo & 1.24 & 2.55 & 2.23 & 3.06 & 1.67 & 2.53 \\
\hline & & & & & & \\
\hline
\end{tabular}

Note. $M=$ Mean; $S D=$ Standard deviation.

*No statistically significant differences were found in relation to the cutoff points regarding the BDI total scores, the BDI cognitive-affective and the BDI somatic subscales; **Differences between cutoff points at $p<.05$

When analyzing Tables 3 to 5, it is possible to observe that, in the total sample, the values of the BDI total scores and the BDI cognitiveaffective subscale decrease over the years, although slightly. The opposite happens with the BDI somatic subscale (Table 3). The same happens with the sample of carriers, except for the BDI somatic subscale and, for this sample, the value of the subscale rises at a cutoff of point of 7 years and goes back down at a cut- 
Table 5

Results of the BDI Total Scores and Subscales $(M, S D$ and $\alpha)$ at the Three Cutoff Points (4, 7 and 10 years) for the Non-Carriers Sample

\begin{tabular}{|c|c|c|c|c|c|c|}
\hline \multirow{2}{*}{ Variable } & \multicolumn{2}{|c|}{4 Years } & \multicolumn{2}{|c|}{7 Years } & \multicolumn{2}{|c|}{10 Years } \\
\hline & $M$ & $S D$ & $M$ & $S D$ & $M$ & $S D$ \\
\hline \multirow{2}{*}{ BDI Total Scores } & 4.41 & 6.91 & 5.17 & 7.64 & 6.13 & 4.97 \\
\hline & \multicolumn{2}{|c|}{$(\alpha=.895)$} & \multicolumn{2}{|c|}{$(\alpha=.918)$} & \multicolumn{2}{|c|}{$(\alpha=.709)$} \\
\hline \multirow{2}{*}{ BDI Cognitive-Affective Subscale } & 2.83 & 4.80 & 3.34 & 5.35 & 3.19 & 3.23 \\
\hline & \multicolumn{2}{|c|}{$(\alpha=.858)$} & \multicolumn{2}{|c|}{$(\alpha=.893)$} & \multicolumn{2}{|c|}{$(\alpha=.638)$} \\
\hline \multirow{2}{*}{ BDI Somatic Subscale } & 1.59 & 2.59 & 3.43 & 3.56 & 2.94 & 2.49 \\
\hline & \multicolumn{2}{|c|}{$(\alpha=.758)$} & \multicolumn{2}{|c|}{$(\alpha=.790)$} & \multicolumn{2}{|c|}{$(\alpha=.458)$} \\
\hline
\end{tabular}

Note. $M=$ Mean; $S D=$ Standard deviation.

*No statistically significant differences were found in relation to the cutoff points regarding the BDI total scores, the BDI cognitive-affective and the BDI somatic subscales.

off point of 10 years (Table 4). In relation to symptomatic carriers (Table 4), the values of the BDI total scores and the two subscales decrease as the years pass. The same happens in the sample of non-symptomatic carriers (Table 4), although for the BDI total scores and the BDI somatic subscale a slight rise occurs at the cutoff point of 7 years. Interestingly, in the sample of non-carriers, the values of the BDI total scores increase as the cutoff points increase as well. In relation to the BDI cognitive-affective subscale and the BDI somatic subscale, however, the values rise at a cutoff point of 7 years and decrease at the cutoff point of 10 years (Table 5). This fact contradicts the initial hypothesis that the depression's levels would increase for carriers and decrease for non-carriers in the middle- and long-term psychological impact after PST disclosure result and the oncoming age of onset of the disease.

\section{Comparison of the Means for the BDI Total Scores and the Two Subscales, with the Socio-Demographic Variables}

The BDI's means with all independent variables were analyzed. For some of them, however, no statistically significant values were found. That was the case of gender, marital status, type of disease, contact with the disease, neurological examination and cutoff points.
Nevertheless, women presented overall higher averages than men, concerning the BDI total scores and the two BDI subscales values.

Significant differences were, however, found regarding age, profession, changes in life, test result, current state, carriers with symptoms, psychological support, and the difficulty to talk about the disease (data presented in Table 6).

As Table 6 shows, carriers present higher means in the BDI total scores and the BDI somatic subscale values. Regarding the current clinical status, it is possible to verify that carriers already with symptoms - FAP carriers with the disease and which underwent liver transplantation - where the ones presenting higher means both in the BDI total scores as in the BDI subscales scores. It is also worth noting that subjects who have never had psychological support consultations present lower scores either in the BDI total scores or in subscales. It is important to highlight that the highest values of the BDI total scores and subscales are present on those individuals who consider the matter of the disease uncomfortable and who have undergone substantial changes in their lives.

Regarding the variable profession, pensioners and subjects with professions of some responsibility ( $3^{\text {rd }}$ Graffar index) are those with the highest values for the BDI total scores and for BDI subscales. 
Table 6

Mean Comparison for the BDI Total Scores and Subscales, and Socio-Demographic Variables

\begin{tabular}{|c|c|c|c|c|c|c|c|c|c|c|c|c|}
\hline & \multicolumn{4}{|c|}{ BDI Total Scores } & \multicolumn{4}{|c|}{$\begin{array}{l}\text { BDI Cognitive-affective } \\
\text { Subscale }\end{array}$} & \multicolumn{4}{|c|}{ BDI Somatic Subscale } \\
\hline & $n$ & $M$ & $F$ & $p$ & $n$ & $M$ & $F$ & $p$ & $n$ & $M$ & $F$ & $p$ \\
\hline \multicolumn{13}{|l|}{ PST Result } \\
\hline Non-Carrier & 87 & 5.08 & \multirow{2}{*}{5.14} & \multirow{2}{*}{.025} & 87 & 3.13 & \multirow{2}{*}{3.69} & \multirow{2}{*}{.056} & 87 & 1.95 & \multirow{2}{*}{6.01} & \multirow{2}{*}{.01} \\
\hline Carrier & 104 & 7.67 & & & 106 & 4.60 & & & 105 & 3.14 & & \\
\hline \multicolumn{13}{|l|}{ Current Clinical Status } \\
\hline Non-Carrier & 86 & 5.12 & & & 86 & 3.14 & & & 86 & 1.98 & & \\
\hline Asymptomatic Carrier & 70 & 5.26 & & & 71 & 3.45 & & & 70 & 1.76 & & \\
\hline Symptomatic Carrier & 26 & 12.69 & 8.54 & .001 & 27 & 6.74 & 3.98 & .009 & 27 & 6.22 & 17.82 & .001 \\
\hline $\begin{array}{l}\text { Liver Transplanted } \\
\text { (FAP carriers) }\end{array}$ & 7 & 11.43 & & & 7 & 6.14 & & & 7 & 5.29 & & \\
\hline
\end{tabular}

Absence of symptoms (carriers)

$\begin{array}{lccccccccccc}\text { Yes } & 65 & 4.52 & & 66 & 3.00 & & 65 & 1.48 & \\ \text { Perhaps } & 8 & 13.88 & 14.17 & .001 & 8 & 7.50 & 5.18 & .001 & 9 & 6.11 & 23.86 .001 \\ \text { No } & 27 & 12.89 & & 28 & 7.11 & & & 27 & 6.11 & \end{array}$

Psychological Support

$\begin{array}{lllllllllllll}\text { Never } & 53 & 4.91 & & 53 & 2.87 & & 53 & 2.04 & \\ \text { Once } & 23 & 10.04 & 6.22 & .003 & 25 & 6.08 & 5.33 & .006 & 24 & 4.13 & 4.83 & .010 \\ \text { Often } & 28 & 10.96 & & & 28 & 6.57 & & & 28 & 4.39 & & \end{array}$

Uncomfortable Issue

\begin{tabular}{|c|c|c|c|c|c|c|c|c|c|c|c|}
\hline Yes & 17 & 9.24 & & & 17 & 6.35 & & & 17 & 2.28 & \\
\hline Perhaps & 13 & 5.62 & 3.40 & .021 & 13 & 3.31 & 4.16 & .009 & 13 & 3.31 & 1.35 \\
\hline No & 55 & 3.62 & & & 55 & 2.04 & & & 55 & 1.58 & \\
\hline
\end{tabular}

Life-Events

$\begin{array}{lllllllllllll}\text { Yes } & 52 & 9.56 & & & 52 & 5.84 & & & 53 & 3.72 & 2.44 & .121 \\ \text { No } & 52 & 5.79 & & & 54 & 3.41 & & & 52 & 2.52 & \end{array}$

Profession

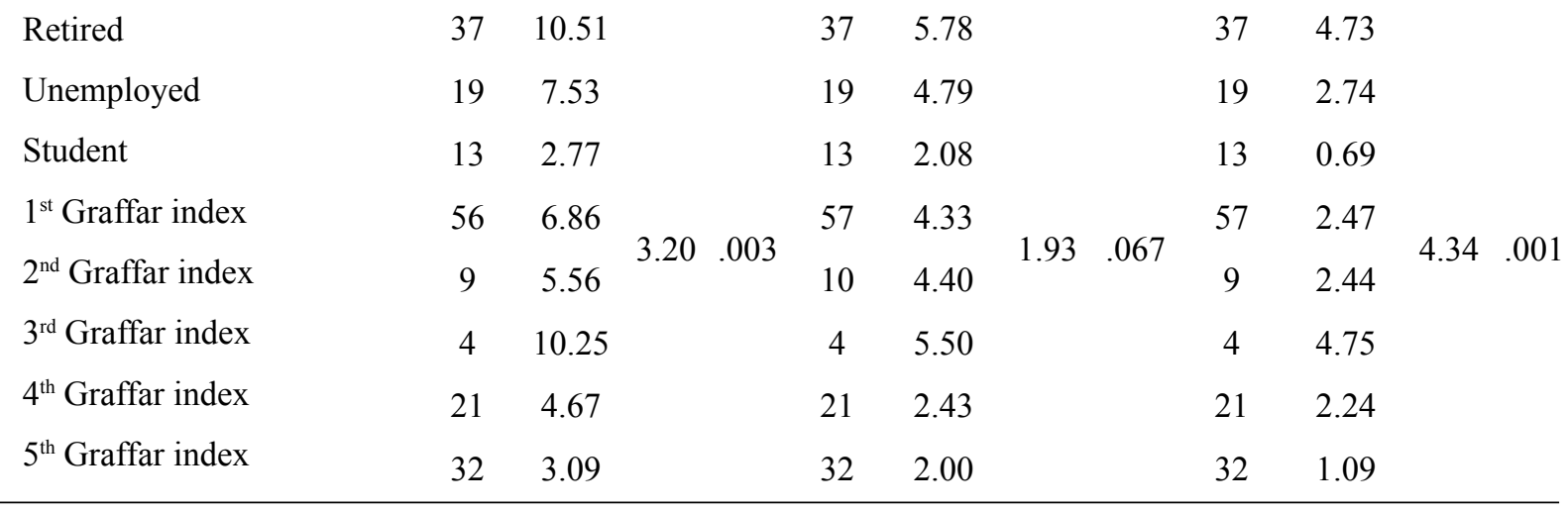

Note. $M=$ Mean; $F=$ Snedecor's $F$ distribution or the Fisher-Snedecor distribution; $p=p$-value. PST = pre-symptomatic tests; $\mathrm{FAP}=$ familial amyloidotic polyneuropathy. 


\section{Discussion and Conclusions}

The results obtained are acceptable considering the internal consistency of the BDI scale, since the $\alpha$ values for all groups of subjects were, in general, around .80 , leading to the conclusion that it is also a valid instrument to study this specific sample. This high internal consistency agrees with what was found in standardization studies for the Portuguese population of VazSerra and Pio-Abreu (1973a, 1973b).

From the performed descriptive analysis, it was possible to confirm what previous studies have reported (Bloch, Fahy, Fox, \& Hayden, 1989; Gargiulo et al., 2009; Paneque et al., 2007), that is, that the female population tends to present higher levels of psychopathology and, in general, this happens in relation to the depressive disorder, which women are more likely to suffer than men (Kessler, 2003). Generally, the present study shows that the larger number of subjects who received the result of carrier present higher values of psychopathology - depression, in the case - than those receiving the result of noncarrier, as others studies had already shown before (Decruyenaere et al., 2003; Gargiulo et al., 2009; Timman et al., 2004).

As previous studies had already reported (Broadstock, Michie, \& Marteau, 2000; Duisterhof, Trijsburg, Niermeijer, Roos, \& Tibben, 2001; Meiser \& Dunn, 2000; Tibben et al., 1997), the presented analysis seems to support the idea of a small negative psychological impact (middle- and long-term), resulting from the completion of PST and knowledge of the subjects genetic status. The hypothesis of the self-selection which states that individuals emotionally and psychologically better prepared to perform the PST are those who, in fact, had performed it years before, and who return to the successive follow-ups (Codori et al., 1994; Paneque et al., 2007; Rolim et al., 2006; Tibben, 2007), seem to continue to explain the tendency of the results obtained. Thus, it is possible to infer about the possibility of these same individuals to be more receptive to respond to the questionnaires, years later, as Timman et al. (2004) have mentioned. According to the same authors, people who continued to attend the follow-ups years later, would be those that would present less psychological disturbance from the beginning and who have never gave up the follow-ups, and who did not present avoidance mechanisms towards the reality of the disease.

When analyzing the group of carriers and focusing on their current status, it could be observed that those who have begun in the meanwhile to present symptoms, as well as, in the case of FAP patients, those who had been transplanted, presented average values that pointed out to mild depression or very close to it, respectively. The mean of non-symptomatic carriers were found to be very similar to noncarriers, corroborating what Licklederer, Wolff, and Barth (2008) had also observed, stating that no difference between these two conditions seem to exist. This fact seems to reveal that while representing a reality that is more or less distant, and that is more or less expected but that has not been yet experienced and, therefore, it is not real, the idea of the disease does not affect the emotional life of the subjects that only when facing the first symptoms, seem to feel compelled to encounter this reality and, perhaps, to try to mentally and emotionally elaborate it for the first time. This point of view becomes even more clear, when analyzing the results relating the question "Do you continue without presenting any symptoms of the disease?". The subjects answering "no" or "maybe" were the ones presenting values which revealed mild depression (i.e., it seems that to establish the existence of symptoms apparently increases the degree of depression, although the suspicion of the disease existence may already be disturbing to the subjects). These findings confirm the reference made in two previous studies of Tibben (2007) and Timman et al. (2004) about the importance of further investigation on the avoidance mechanisms used by carriers that are still asymptomatic.

It was found that the individuals who are retired presented higher depression scores and the same happened with individuals whose profession refers to the $3^{\text {rd }}$ Graffar Index - professions of medium and technical level. The former may 
correspond to those individuals already unable to work due to the disease. The values found in the latter will not be probably related with the PST and subsequent genetic status result, but only with the valorization of the labor reality that is felt as unsatisfactory.

It was also found that individuals who have had, over the years, one or more psychological consultations, were those presenting the highest means, corroborating, once more, the idea that they seem to be the ones more disturbed (i.e., those who ask for, or use, psychological help).

When faced with the question of the existence of remarkable life events in recent years, the group of carriers confirming these events was the one who presented higher means. The fact that these events are mostly described as lost or disease of loved ones may be the cause of a more depressive experience, which reflects into higher BDI means.

When trying to analyze the mean values of the BDI total scores found, depending on the time elapsed since the PST, no statistically significant differences were found when comparing carriers with non-carriers, an interesting result. The exception happens precisely in the group of symptomatic carriers, already sick, where statistically significant differences were found in function of time. Very high values were found, on the frontier of moderate depression, in individuals who underwent the PST for four years and already presented symptoms. Patients who took the test 7 years ago presented means very close to mild depression and the symptomatic carriers who performed the PST 10 years ago presented much lower mean values very similar to the means of non-carriers or asymptomatic carriers.

This evidence is important in two situations:

1. On one hand, how long ago have the subjects performed the PST and, for asymptomatic patients, the threat of approaching the age at onset of the first symptoms does not seem to affect the individuals. Whether the subjects live or not with the symptoms of the disease;

2. On the other hand, those subjects who had apparently little time since the communica- tion of the result of carrier until the onset of the first symptoms are the ones that are more depressive. This situation no longer occurs for those individuals who performed the PST 10 years ago and are, therefore, more familiar with the disease.

\section{Limitations of the Study}

This study is a cross-sectional one, with a possible response limitation, since only 203 subjects answered out of the 686 contacted, and so $70.4 \%$ potential participants did not integrate the study. The consequence of this fact is that no clear conclusions can be drawn on the development of the depression. The subjects were not monitored for current use of antidepressant and/or anxiolytic medication at the moment of the evaluation, which may account as an attenuating factor, because it contributes to minimize the depression. The categorization of the time since PST into three different cutoff points of 4,7 and 10 years weakens the study, because the differences found at different times are not significant.

\section{References}

Almqvist, E. W., Bloch, M., \& Hayden, M. (1999). A worldwide assessment of the frequency of suicide, suicide attempts, or psychiatric hospitalization after predictive testing for Huntington Disease. American Journal of Human Genetics, 64(5), 1293-1304. doi:10.1086/302374

Almqvist, E. W., Brinkman, R. R., Wiggins, S., \& Hayden, M. R. (2003). Canadian Collaborative Study of Predictive Testing. Psychological consequences and predictors of adverse events in the first 5 years after predictive testing for Huntington's disease. Journal of Clinical Genetics, 64(4), 300-309. doi:10.1034/j.13990004.2003.00157.x

Beck, A., Mendelson, M., Mock, J., \& Erbaugh, J. (1961). An inventory for measure depression. Archives of General Psychiatry, 4, 561-571.

Beck, A. T., Steer, R. A., Ball, R., \& Ranieri, W. F. (1996). Comparison of Beck Depression Inventories -IA and -II in Psychiatric Outpatients. Journal of Personality Assessment, 67(3), 588597. doi:10.1207/s15327752jpa6703_13 
Bloch, M., Fahy, M., Fox, S., \& Hayden, M. (1989). Presymptomatic testing for Huntington disease: II. Demographic characteristics, life-style patterns, attitudes, and psychosocial assessments of the first fifty-one test candidates. American Journal of Medical Genetics, 32(2), 217-224. doi:10.1002/ajmg.1320320215

Broadstock, M., Michie, S., \& Marteau, T. M. (2000). The psychological consequences of predictive genetic testing: A systematic review. European Journal of Human Genetics, 8(10), 731-738. doi:10.1038/sj.ejhg.5200532

Codori, A. M., Hanson, R., \& Brandt, J. (1994). Selfselection in predictive testing for Huntington's disease. American Journal of Medical Genetics, 54(3), 167-173. doi:10.1002/ajmg.1320540303

Codori, A. M., Slavney, P. R., Rosenblatt, A., \& Brandt, J. (2004). Prevalence of major depression one year after predictive testing for Huntington's disease. Journal of Genetic Testing and Molecular Biomarkers, 8(2), 114-119. doi:10.1089/gte.2004.8.114

Coutinho, P. (1996). Clinical features, natural history and epidemiology in the Machado-Joseph disease. In J. Sequeiros (Ed.), The Predictive Test of Machado-Joseph Disease (pp. 15-22). Porto, Portugal: Institute of Molecular and Cell Biology.

Decruyenaere, M., Evers-Kiebooms, G., Cloostermans, T., Boogaerts, A., Demyttenaere, K., Dom, R., \& Fryns, J. P. (2003). Psychological distress in the 5-year period after predictive testing for Huntington's disease. European Journal of Human Genetics, 11(1), 30-38. doi:10.1038/ sj.ejhg.5200913

Decruyenaere, M., Evers-Kiebooms, G., Cloostermans, T., Boogaerts, A., Demyttenaere, K., Dom, R., \& Fryns, J. P. (2004). Predictive testing for Huntington's disease: Relationship with partners after testing. Journal of Clinical Genetics, 65(1), 24-31. doi:10.1111/j.2004.00168.x

Decruyenaere, M., Evers-Kiebooms, G., \& Van Den Berghe, H. (1997). Non-participation in predictive testing for Huntington's Disease: Individual decision-making, personality and avoidant behavior in the family. European Journal of Human Genetics, 5(6), 351-363.

Duisterhof, M., Trijsburg, R. W., Niermeijer, M. F., Roos, R. A. C., \& Tibben, A. (2001). Psychological studies on Huntington's disease: Making up the balance. Journal of Medical Genetics, 38(12), 852-861. doi:10.1136/jmg.38.12.852
Gargiulo, M., Lejeune, S., Tanguy, M., LahlouLaforet, K., Faudet, A., Cohen, D., ...Durr, A. (2009). Long-term outcome of presymptomatic testing in Huntington disease. European Journal of Human Genetics, 17, 165-171. doi:10.1038/ ejhg.2008.146

Gonzalez, C., Gomes, E., Kazachkova, N., Bettencourt, C., Raposo, M., Taylor, T., ...Lima, M. (2012). Psychological well-being and family satisfaction levels five years after being confirmed as a carrier of the MachadoJoseph Disease mutation. Journal of Genetic Testing and Molecular Biomarkers, 16(12), 1-6. doi:10.1089/gtmb.2011.0370

Kessler, R. C. (2003). Epidemiology of women and depression. Journal of Affective Disorders 74(1), 5-13. doi:10.1016/S0165-0327(02)00426-3

Lêdo, S. (2002). The first day of the rest of their lives. Some psychological aspects of Amyloidosis (Master's thesis, Institute of Applied Psychology, Lisbon, Portugal).

Lêdo, S., Leite, A., \& Sequeiros, J. (2013). Anxiety and pre-symptomatic testing for neurodegenerative disorders. Open Journal of Genetics, 3, 1426. doi:10.4236/ojgen.2013.32A3003

Leite, A. (2006). Psychosocial Determinants of Adherence for pre-symptomatic testing of the late onset neurological genetic diseases (Doctoral thesis, Instituto de Ciências Biomédicas Abel Salazar, University of Porto, Portugal).

Lerman, C. (1997). Psychological aspects of genetic testing: Introduction to the special issue. Journal of Health Psychology, 16(1), 3-7. doi:10.1037/ h0092702

Licklederer, C., Wolff, G., \& Barth, J. (2008). Mental health and quality of life after genetic testing for Huntington disease: A long-term effect study in Germany. American Journal of Medical Genetics, 146A(16), 2078-2085. doi:10.1002/ ajmg.a.32423

MacLeod, R., Tibben, A., Frontali, M., EversKiebooms, G., Jones, A., Martinez-Descales, A., ...Editorial Committee and Working Group 'Genetic Testing Counselling' of the European Huntington Disease Network. (2013). Recommendations for the predictive genetic test in Huntington's Disease. Journal of Clinical Genetics, 83(3), 221-231. doi:10.1111/j.13990004.2012.01900.x

Meiser, B., \& Dunn, S. (2000). Psychological impact of genetic testing for Huntington disease: An 
update of the literature. Journal of Neurology, Neurosurgery \& Psychiatry, 69(5), 574-578. doi:10.1136/jnnp.69.5.574

Michie, S., Bobrow, M., \& Marteau, M. (2001). Predictive genetic testing in children and adults: A study of emotional impact. Journal of Medical Genetics, 38(8), 519-526. doi:10.1136/ jmg.38.8.519

Norusis, M. J. (2011). PASW Statistics 19 Guide to Data Analysis. Upper Saddle River, NJ: Pearson.

Paneque, H. M., Lemos, C., Sousa, A., Velázquez, P. L., Fleming, M., \& Sequeiros, J. (2009). Role of the disease in the psychological impact of pre-symptomatic testing for SCA2 and FAP ATTRV30M: Experience with the disease, kinship and gender of the transmitting parent. Journal of Genetic Counseling, 18(5), 483-493. doi:10.1007/s10897-009-9240-1

Paneque, H. M., Prieto, A. L., Reynaldo, R. R., Cruz, M. T., Santos, F. N., Almaguer, M. L., ...Heredero, B. L. (2007). Psychological aspects of presymptomatic diagnosis of spinocerebellar Ataxia type 2 in Cuba. Journal of Community Genetics, 10(3), 132-139. doi:10.1159/000101754

Pinto-Gouveia, J. (1990). Cognitive factors of vulnerability to depression (Study of their interaction with life events) (Doctoral thesis, University of Coimbra, Portugal).

Rolim, L., Leite, A., Lêdo, S., Paneque, M., Sequeiros, J., \& Fleming, M. (2006). Psychological aspects of pre-symptomatic testing for Machado-Joseph disease and familial amyloid polyneuropathy type I. Journal of Clinical Genetics, 69(4), 297305. doi:10.1111/j.1399-0004.2006.00606.x

Saraiva, M. J., \& Costa, P. (1986). Familial Amyloidotic Polyneuropathy, Portuguese type: Phenotype and genotype. In M. L. Sales-Luís (Ed.), Symposium on peripheral neuropathies (pp. 207-212). Lisbon, Portugal.

Sequeiros, J. (1996a). Classical genetics and molecular genetics in Machado-Joseph disease. In J. Sequeiros (Ed.), The Predictive Test of Machado-Joseph Disease (pp. 33-48). Porto, Portugal: Institute of Molecular and Cell Biology.

Sequeiros, J. (1996b). Genetic counseling and predictive testing in Machado-Joseph disease. In J. Sequeiros (Ed.), The Predictive Test of MachadoJoseph Disease (pp. 97-112). Porto, Portugal: Institute of Molecular and Cell Biology.
Sequeiros, J. (1996c). History of Machado-Joseph Disease. In J. Sequeiros (Ed.), The Predictive Test of Machado-Joseph Disease (pp. 3-14). Porto, Portugal: Institute of Molecular and Cell Biology.

Skirton, H., Goldsmith, L., Jackson, L., \& Tibben, A. (2013). Quality in genetic counselling for presymptomatic testing - Clinical guidelines for practice across the range of genetic conditions. European Journal of Human Genetics, 21, 256260. doi:10.1038/ejhg.2012.174

Takiyama, Y., Nishizawa, M., Tanaka, H., Kawashima, S., Sakamoto, H., Karube, Y., ...Tsuji, S. (1993). The gene for Machado-Joseph disease maps to human chromosome 14q. Journal of Nature Genetics, 4, 300-304.

Tibben, A. (2007). Predictive testing for Huntington's disease [Special issue]. Brain Research Bulletin, 72(2-3), 165-171. doi:10.1016/j.brainresbull.2006.10.023

Tibben, A., Timman, R., Bannink, E., \& Duivenvoorden, H. (1997). Three years follow-up after presymptomatic testing for Huntington's Disease in tested individuals and partners. Journal of Health Psychology, 16(1), 20-35. doi:10.1037/02786133.16.1.20

Timman, R., Roos, R., Maat-Kievit, A., \& Tibben, A. (2004). Adverse effects of predictive testing for huntington disease underestimated: Long-term effects 7-10 years after the test. Journal of Health Psychology, 23(2), 189-197. doi:10.1037/0278-6133.23.2.189

Vaz-Serra, A., \& Pio-Abreu, J. L. (1973a). Measurement of depressive disorders. I - Essay application of Beck Depression Inventory for a Portuguese sample of depressed patients. Journal Medical Coimbra, 20, 623-644.

Vaz-Serra, A., \& Pio-Abreu, J. L. (1973b). Measurement of depressive disorders. II - Preliminary study of new symptom clusters to complement the Beck Depression Inventory. Journal Medical Coimbra, 20, 713-736. 